\title{
Relação atmosfera e dinâmica sedimentar nas praias de Macapá e Maramar -Luis Correia - Piauí - Brasil
}

\author{
Relation atmosphere and sedimentary dynamics on the beaches of Macapá and \\ Maramar - Luís Correia - Piauí-Brazil
}

\author{
Glairton Cardoso Rocha \\ Doutor em Geografia \\ Professor do Instituto Federal de Educação, Ciência e \\ Tecnologia do Piauí (IFPI), Brasil \\ glairtongeo@ifpi.edu.br
}

\begin{abstract}
Resumo
Os ambientes costeiros são caracterizados do ponto de vista ambiental por apresentarem dinâmica acentuada, evidenciada pelos intensos fluxos de matéria e energia. Isso se deve à interação de agentes atmosféricos, oceanográficos e continentais, que realizam rápidas modificações. A atmosfera controla boa parte dessas transformações, que se refletem na dinâmica sedimentar como, por exemplo, no calibre dos sedimentos. O presente trabalho possui como objetivo analisar os desdobramentos do comportamento atmosférico sobre a dinâmica sedimentar das praias de Macapá e Maramar, localizadas no município de Luis Correia, litoral do Piauí. Para isso, foram usados dados secundários de diversas fontes como os de hidrometeorologia da Secretaria de Meio Ambiente e Recursos Naturais do Estado do Piauí, no período de 1913 a 2000. Dados coletados pelo Instituto Nacional de Meteorologia (INMET), de 1961 a 1990 (Normais Climáticas), e de 2010 a 2014. Informações da Empresa Brasileira de Pesquisa Agropecuária (EMBRAPA), de 1978 a 1987. Os dados sedimentares foram conseguidos através de análise granulométrica de 30 amostras coletadas em campo, nos períodos chuvosos e de estiagem. Os resultados mostraram que, devido à influência de fatores locais, apenas o perfil 3 demonstrou comportamento sazonal de maneira mais significativa, enquanto os perfis 1 e 2 não apresentaram mudanças sazonais significativas, e os perfis 4 e 5 tiveram esse comportamento atenuado.
\end{abstract}

Palavras-chave: precipitação pluviométrica, dinâmica sedimentar, sazonalidade

\begin{abstract}
The Coast environments are characterized, by the environmental point of view, for showing marked dynamics, evidenced by the intense flow of matter and energy. This happens because of the interaction of atmospheric, oceanographic and continental agents, which promote fast changes. The atmosphere controls a good share of these changes, which reflect on the sedimentary dynamics like, for example, on the size of the sediments. The present work aims to analyze the development of the atmospheric behavior on the sedimentary dynamics of Macapá and Maramar beaches, sited in the Municipality of Luís Correia, in the coastline of the State of Piauí. For this, secondary data from several sources like those of hydrometeorology of the Secretariat of Environment and Natural Resources of the State of Piauí, in the period from 1913 to 2000, were used. Data gathered by the National Institute of Meteorology (INMET), from 1961 to 1990 (Climatological Normals), and from 2010 to 2014. Brazilian Agricultural Research Corporation (EMBRAPA) information, from 1978 to 1987 . The sedimentary data were gathered through the granulometric analyses of 30 (thirty) samples gathered onsite, in the rainy and drought periods. The results showed that, due to local factors, only profile 3 showed seasonal behavior in a more significant way, whereas profiles 1 and 2 did not show significant seasonal changes, and the profiles 4 and 5 had this behavior eased.
\end{abstract}

Keywords: Precipitation. Sedimentary Dynamics. Seasonality. 


\section{INTRODUÇÃO}

As zonas costeiras são espaços ambientais diferenciados, onde os principais processos são regidos por agentes atmosféricos, continentais e oceanográficos que interagem continuamente provocando mudanças significativas na morfologia das praias (AB'SABER, 2000). As variáveis meteorológicas ditam o ritmo de tais transformações, pois interferem diretamente na disponibilidade e movimentação dos sedimentos em todo o litoral. Além disso, induzem mudanças no comportamento dos parâmetros oceanográficos como, por exemplo, na atuação dos ventos sobre o processo de formação de ondas. A atmosfera é o ponto de partida para a compreensão dos fluxos de matéria e energia das zonas costeiras.

Dessa forma, é interessante atentar para o tratamento dado às variáveis atmosféricas a partir dos estudos climáticos no Brasil. Tavares (1976) afirma que a concepção sorreana de clima (SORRE, 1951), que dá ênfase aos estados atmosféricos e sua sucessão habitual, norteou a produção em Climatologia Geográfica no país a partir da segunda metade do século XX. Monteiro (1971) propôs a partir de tal concepção climática a proposta da análise rítmica, com ênfase na precipitação. Para esse autor a maneira de analisar o clima seria através do ritmo climático, observando a variabilidade pluviométrica. Para isso, Monteiro propôs a "análise rítmica", dedicando-se ao estudo dos anos padrões excepcionais (chuvoso e seco) e dos anos padrões normais.

Apesar de não objetivar realizar a análise rítmica da área de estudos, ressalta-se que assim como nos estudos de climatologia geográfica, deve-se atentar para a importância da precipitação pluviométrica como ponto de partida para o entendimento de parte da dinâmica natural litorânea.

A quantidade e a distribuição das chuvas irá se refletir em outras variáveis atmosféricas e, consequentemente, na movimentação sedimentar das zonas costeiras, intensificando ou atenuando os fluxos de matéria e energia nas zonas costeiras, mais especificamente nas praias.

A precipitação é um fator de grande importância para a evolução das praias, pois influenciará na disponibilidade de sedimentos para a zona costeira, aumentando a vazão dos cursos fluviais e, consequentemente, a quantidade de sedimentos continentais que chega à costa.

Durante os períodos chuvosos, comumente verificam-se perfis de acumulação de sedimentos, não só devido à maior quantidade de partículas que alcança a costa (por conta do aumento sazonal da vazão das bacias hidrográficas), mas também devido ao efeito moderador que a precipitação e a umidade exercem sobre os processos de deflação eólicos, que transportam material da faixa de praia para as porções de pós-praia. No entanto, alguns eventos excepcionais podem influenciar esse comportamento como, por exemplo, a entrada de ondas do tipo swell, que são ondas de alta energia formadas por ação dos ventos regionais e possuem uma grande capacidade de 
movimentação sedimentar. Assim, esse tipo de evento durante a estação chuvosa pode acarretar o desenvolvimento de perfis típicos de praias erodidas.

Um exemplo de interação entre a precipitação pluviométrica e a disponibilidade de sedimentos foi observado em Luís Correia (BITTENCOURT, et. al., 1990), onde o movimento de sedimentos da faixa de praia para os campos de dunas é intensificado nos anos em que os índices de precipitação ficam abaixo das médias anuais. Esse evento está totalmente condicionado às variações sazonais na precipitação atmosférica, pois um bloqueio do deslocamento da ZCIT para o sul, durante o verão e outono, resulta em significativo decréscimo da precipitação e concomitante aumento do transporte de sedimentos para a zona de pós-praia, por processos de deflação eólicos. Isso ocorre, pois, nos anos com desvios negativos de precipitação, as taxas de umidade do ar são menores, acelerando as taxas de evaporação. Dessa forma, o filme de umidade que reveste os sedimentos do estirâncio é rapidamente retirado, diminuindo a coesão dos sedimentos arenosos e aumentando a eficiência do transporte eólico.

Dessa maneira, o presente trabalho possui como objetivo analisar os desdobramentos do comportamento atmosférico sobre a dinâmica sedimentar das praias de Macapá e Maramar, localizadas no município de Luis Correia, litoral do Piauí.

\section{METODOLOGIA}

\subsection{Análise Climática}

Foram selecionadas algumas variáveis atmosféricas que controlam direta ou indiretamente os processos costeiros, como a precipitação, umidade relativa do ar, evaporação, bem como velocidade e direção de ventos. No que se refere aos dados meteorológicos, foram coletadas informações de precipitação da estação Luís Correia, contidas no banco de dados da Gerência de Hidrometeorologia da Secretaria de Meio Ambiente e Recursos Naturais do Estado do Piauí, no período 1913 a 2000, disponíveis em Lima(2005). Para as demais variáveis, optou-se pela utilização de dados das estações localizadas no município de Parnaíba devido a maior disponibilidade de informações e, também, pelo fato da proximidade geográfica e similaridade das condições ambientais. Os dados utilizados são oriundos da compilação de valores médios coletados pelo Instituto Nacional de Meteorologia - INMET, no período de 1961 a 1990 e publicados na obra "Normais Climatológicas do Brasil 1961 a 1990" (INSTITUTO NACIONAL DE METEOROLOGIA, 1996) bem como, informações do Banco de Dados Meteorológicos para Ensino e Pesquisa (BDMEP), do período 2010 a 2014, também do INMET, disponíveis em seu sítio eletrônico. Além disso, foram usadas informações do Boletim Agrometeorológico (EMBRAPA 
1990) e consulta bibliográfica. Os dados foram tabulados em planilha eletrônica e tratados estatisticamente para a confecção de gráficos.

As informações em conjunto, permitiram realizar uma análise do comportamento regular da atmosfera e analisar a variabilidade da precipitação dentro do intervalo histórico. Através das informações mais recentes (2010 - 2014), foi possível verificar as possíveis interações entre o comportamento ressente da atmosfera e a granulometria dos sedimentos de praia.

\subsection{Caracterização sedimentar}

Para Suguio (2003), a análise granulométrica permite realizar uma descrição mais precisa dos sedimentos, fornece características de determinados ambientes deposicionais, além de informar os processos físicos atuantes durante a deposição e pode ser relacionada a outras propriedades como porosidade e permeabilidade.

Foi realizada amostragem sedimentar na superfície em cinco perfis nos diferentes segmentos (antepraia, estirâncio e pós-praia) com o objetivo de verificar o intervalo granulométrico característico do trecho em estudo. A coleta sedimentar aconteceu em pontos estrategicamente definidos, em função do grau de ocupação e do gradiente de declividade, (ROCHA, 2008; 2015).

Os sedimentos foram coletados em três pontos (antepraia, estirâncio e pós-praia) ao longo de cada um de cinco perfis, de acordo com a ocorrência da ocupação humana, mesmo que incipiente. Os locais escolhidos, de leste para oeste, possuem as seguintes localizações aproximadas: (P1)

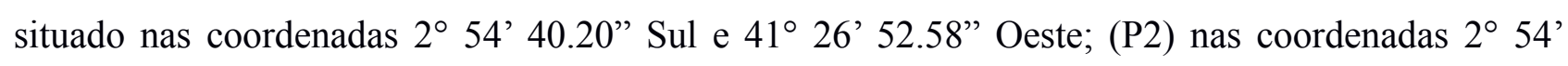

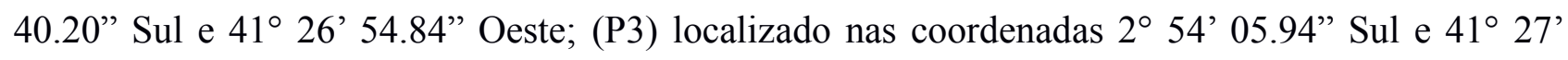
27.43" Oeste; (P4) localizado nas coordenadas $2^{\circ}$ 54'06.18” Sul e $41^{\circ} 27$ ' 36.19" Oeste e (P5) localizado nas coordenadas $2^{\circ} 54^{\prime} 06.18^{\prime \prime}$ Sul e $41^{\circ} 27^{\prime} 43.58^{\prime \prime}$ Oeste. A localização dos perfis é mostrada na figura 1.

Os perfis de coleta 1 e 2 foram estabelecidos na praia de Macapá, nas adjacências da desembocadura fluvial dos rios Cardososo/Camurupim, mais especificamente a oeste da foz. A praia neste local possui estirâncio bem desenvolvido, além de apresentar mudanças significativas na posição da arrebentação das ondas, que é influenciada pela posição da maré e pela morfologia do fundo, indicando a existência de bancos arenosos submersos. Assim, durante as preamares, as ondas realizam trabalho efetivo sobre a faixa de praia, enquanto que,durante as baixa-mares, a arrebentação ocorre ao largo, caracterizando-a momentaneamente como praia abrigada.

Os outros três perfis de coleta foram distribuídos na faixa de praia de Maramar, que é mais estreita e onde se verifica um trabalho mais efetivo das ondas no ambiente praial, em ambas as posições de marés. 


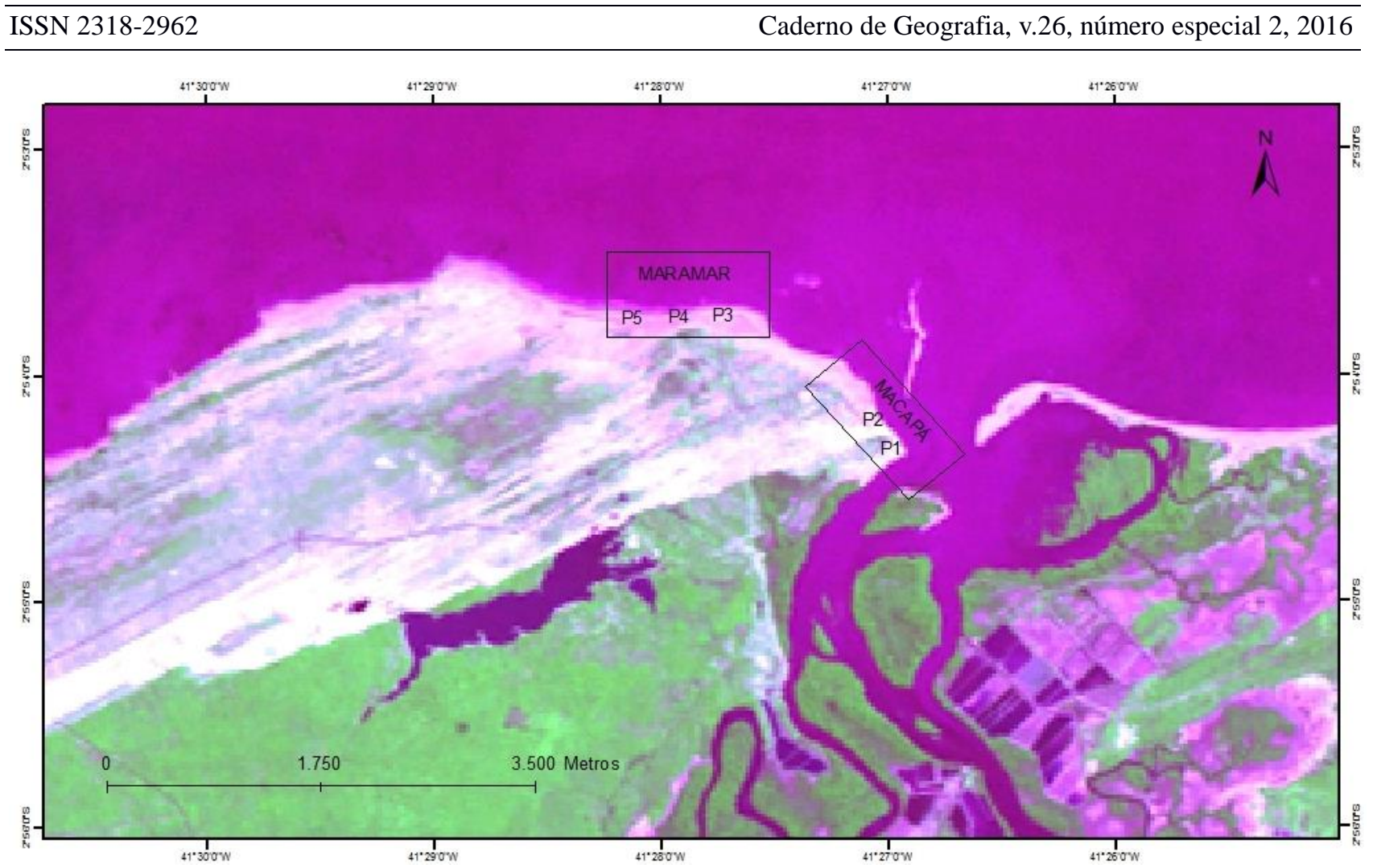

Figura 1 - Localização dos perfis de coleta sedimentar. Fonte: Imagem do Instituto Nacional de Pesquisas. Espaciais INPE (2015c).Organizado pelo autor.

A amostragem foi realizada uma vez durante a estação chuvosa, em março de 2014, e outra na estação de estiagem, em novembro de 2014, durante as baixa-mares de sizígia. Assim, foi possível verificar a ocorrência de mudanças sazonais cíclicas no calibre dos sedimentos em função dos parâmetros atmosféricos (precipitação, umidade, evaporação e velocidade dos ventos).

O material coletado foi acondicionado em sacos plásticos e etiquetado com as seguintes informações: identificação do ponto, compartimento, período da coleta (estação chuvosa ou seca), data e hora da coleta. As amostras foram tratadas no Laboratório de Geologia e Geomorfologia Costeira e Oceânica (LGCO) da Universidade Estadual do Ceará (UECE).

Após a coleta, as amostras foram analisadas em laboratório, seguindo as seguintes etapas:

a) As amostras foram imersas em água durante 24 horas para a retirada dos sais;

b) Após esse processo, as amostras foram secas em estufa, a $60^{\circ} \mathrm{C}$ (temperatura que garante a preservação dos argilominerais);

c) Posteriormente realizou-se o quarteamento das amostras para preservar a homogeneidade;

d) Depois de quarteada, separou-se uma fração correspondente a 100 gramas.

Em seguida executou-se o peneiramento úmido, separando a fração fina e os sais da fração de maior calibre. Nesse processo foi utilizada uma peneira com malha de $0,062 \mathrm{~mm}$ retendo os sedimentos com diâmetro superior (areia muito fina a cascalho). Os sedimentos finos (silte e argila), 
caso ocorressem, ficariam retidos em um recipiente disposto abaixo da peneira durante esse processo (não foram encontradas frações finas nas amostras). Após o peneiramento úmido a fração de maior calibre foi levada novamente à estufa para nova secagem.

Posteriormente, realizou-se o peneiramento feito com os sedimentos de diâmetro superior, utilizando um agitador mecânico do tipo "Rotap sieve-shaker", e um jogo com 12 peneiras com malhas que variam de $2,830 \mathrm{~mm}$ a $0,06 \mathrm{~mm}$ ( ( ${ }^{-} 2$ a 4 [phi]), durante 15 minutos.

As frações retidas em cada malha foram pesadas em balança de precisão.

Por fim, com os valores obtidos, realizou-se o tratamento estatístico dos resultados utilizando o software Sistema de Análise Granulométrica (SAG), desenvolvido pelo Departamento de Geologia e Geofísica Marinha da Universidade Federal Fluminense - RJ.

A classificação dos sedimentos ocorreu em escala $f i(\phi)$, sendo os valores em $f i$ obtidos pelo logaritmo negativo de base dois do valor em milímetros, conforme equação 1 (MUEHE, 2011):

$$
\phi=\log \left(\mathrm{mm}^{-1}\right) / \log (2),
$$

A classificação textural usada no trabalho foi a proposta por Folk (1968) e discutida por Muehe (2011). A tabela 1 mostra a relação entre o diâmetro expresso em $\phi$ e em milímetros, com a respectiva classificação granulométrica.

Tabela 1 - Classificação granulométrica através do diâmetro

\begin{tabular}{lcc}
\hline \multicolumn{1}{c}{ Classificação } & Tamanho em $\phi$ & Tamanho em mm \\
Areia muito grossa & -1 a 0 & 2 a 1 \\
Areia grossa & 0 a 1 & 1 a 0,5 \\
Areia média & 1 a 2 & 0.5 a 0.25 \\
Areia fina & & \\
Areia muito fina & a a 4 & u, $<$ J a u, vo $\angle J$ \\
Silte & 4 a 8 & 0,0625 a 0,0039 \\
Argila & $>8$ & $<0,0039$ \\
\hline \multicolumn{2}{c}{}
\end{tabular}

Os resultados foram mostrados em tabelas contendo os seguintes parâmetros estatísticos: a classificação pela média gráfica, desvio padrão gráfico e assimetria. No caso, medida de tendência central (média gráfica) e medidas de dispersão (desvio padrão gráfico e assimetria).

A média gráfica (Mz) é expressa pela seguinte equação 2 (MUEHE, 2011):

$$
M z=\frac{\phi_{84}+\phi_{50}+\phi_{16}}{3}
$$

A partir do diâmetro médio em $\phi$ foi calculado o desvio padrão gráfico ( $\square \mathrm{I}$ ) e assimetria gráfica (Sk1), através das equações 3 e 4 (MUEHE, 2011): 


$$
\begin{gathered}
\sigma I=\frac{\phi_{84}-\phi_{16}}{4}+\frac{\phi_{95}-\phi_{5}}{6,6} \\
S k l=\frac{\phi_{84}+\phi_{16}+2 \phi_{50}}{2\left(\phi_{84}-\phi_{16}\right)}+\frac{\phi_{5}+\phi_{95}-2 \phi_{50}}{2\left(\phi_{95}-\phi_{5}\right)}
\end{gathered}
$$

O desvio padrão é uma medida de dispersão em relação à média e à assimetria dos sedimentos. É uma relação entre os parâmetros de tendência central, que são: moda, média e mediana. Quando há distribuição simétrica das partículas, os valores de tendência central são coincidentes. Quando o valor da média supera o da mediana, tem-se uma assimetria negativa com uma tendência às frações mais grosseiras. Quando acontece situação inversa, o valor da média é menor que a mediana, tem-se uma tendência às frações mais finas (MUEHE, 2011). O desvio padrão gráfico $(\square \mathrm{I})$ permite classificar as amostras quanto ao selecionamento, conforme tabela 2.

Tabela 2 : Relação entre desvio padrão gráfico e selecionamento das amostras, proposto por Folk (1968)

\begin{tabular}{cc}
\hline Selecionamento & Desvio \\
Muito bem selecionado & $<0,35$ \\
Bem selecionado & $<\mathrm{I})$ \\
Moderadamente bem selecionado & 0,35 a 0,50 \\
Moderadamente selecionado & 0,50 a 0,71 \\
Mal selecionado & 0.71 a 1,00 \\
Muito mal selecionado & 1,00 a 2,00 \\
Extremamente mal selecionado & 2,00 a 4,00 \\
\hline
\end{tabular}

Fonte: (MUEHE, 2011)

Os valores de assimetria gráfica permitem a seguinte classificação (Tabela 3):

Tabela 3: Classificação da amostra quanto à assimetria

\begin{tabular}{lc}
\hline Classificação da assimetria & Valores \\
Assimetria muito negativa & $<0,35$ \\
Assimetria negativa & 0,35 a 0,50 \\
Simétrica & 0,50 a 0,71 \\
Assimetria positiva & 0.71 a 1,00 \\
Assimetria muito positiva & 1,00 a 2,00 \\
\hline
\end{tabular}

Fonte: (MUEHE, 2011)

No caso das praias, que são depósitos residuais, comumente encontram-se distribuições assimétricas negativas, visto que as frações mais finas são removidas mais facilmente pela ação das ondas (MUEHE, 2011). 


\section{RESULTADOS E DISCUSSÕES}

\subsection{Variabilidade da precipitação}

Pela classificação de Köppen, o clima da região pode ser classificado como um clima do tipo Aw', tropical, com chuvas distribuídas sazonalmente registrando máximas no outono. É possível identificar duas estações bem definidas, uma chuvosa durante os primeiros meses do ano, de janeiro a maio, e outra seca que acontece no segundo semestre, de julho a dezembro, podendo ocorrer chuvas esporádicas nesses dois meses.

As chuvas estão associadas à posição mais meridional da Zona de Convergência Intertropical (NIMER, 1976), que durante os meses de março e abril estimula a formação de nuvens por convecção, causando consequente precipitação (HASTENRATH; HELLER, 1977; NOBRE; SHUKLA, 1996).

A Zona de Convergência Intertropical é caracterizada por duas correntes de ar (ventos alísios), uma meridional, com um componente de sudeste e outra, setentrional, com um componente de nordeste, cuja posição é assinalada por uma faixa de nuvens que pode ser observada nas imagens de satélite a seguir (figura 2), embora, às vezes, a nebulosidade possa estar ausente (AYOADE, 2007).
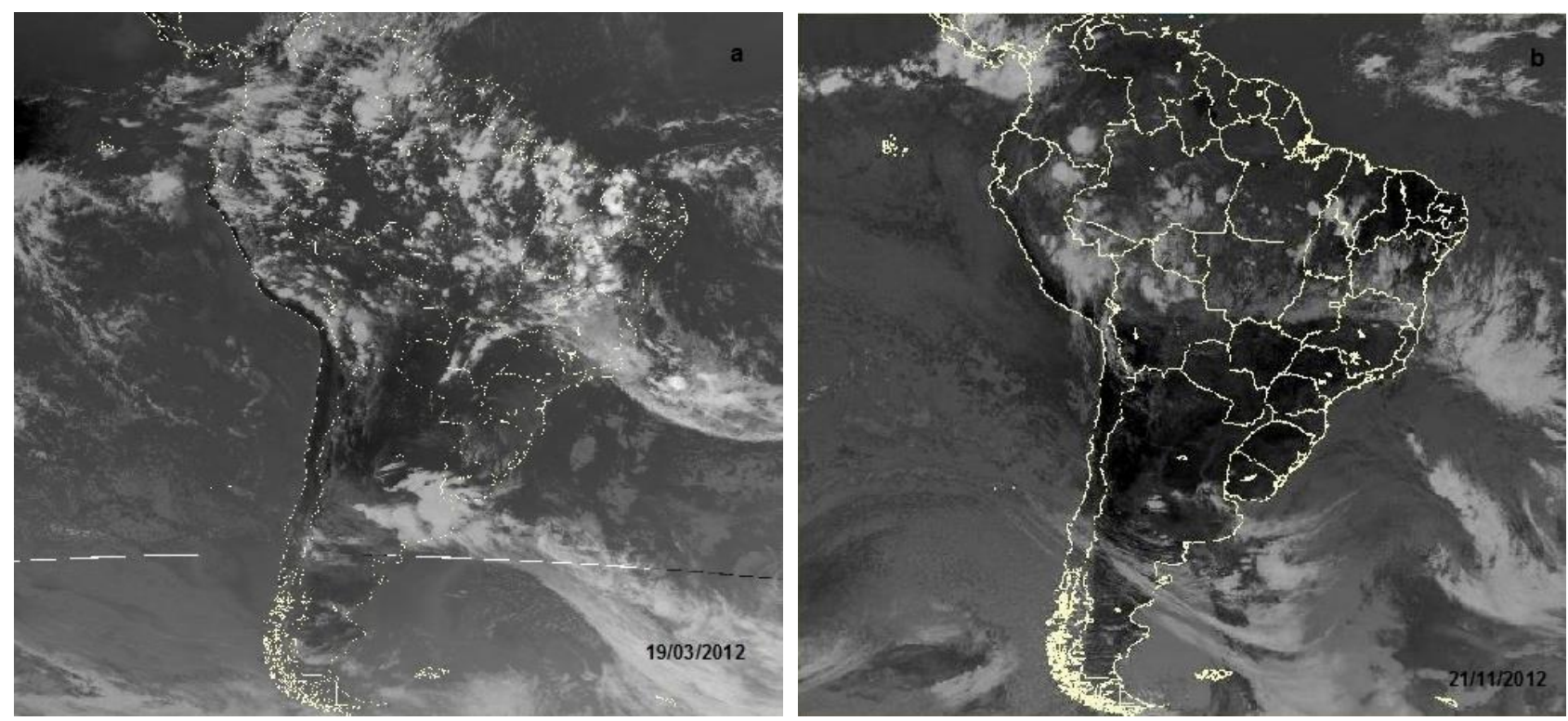

Figura 2 : (a) Presença de nebulosidade provocada pela ZCIT no Norte e Nordeste do Brasil (imagem de 19/03/2012); (b) Ausência de nebulosidade no Piauí em função do deslocamento da ZCIT para o hemisfério Norte (imagem de 21/11/2012). Fonte: Instituto Nacional de Pesquisas Espaciais (2015b)

Segundo Alves et al (2005), a porção norte do Nordeste do Brasil é o fragmento mais influenciado pela ZCIT, especialmente os estados do Maranhão, porções norte e central, Piauí, também no norte e centro, Ceará, Rio Grande do Norte, sertões da Paraíba e Pernambuco. 
Um bloqueio no deslocamento da ZCIT para o hemisfério Sul pode gerar anos com índices de pluviosidade bem discrepantes em relação à normal climatológica local, provocando um desvio negativo na precipitação. Esse fenômeno está associado à temperatura da superfície do Oceano Atlântico, chamado Dipolo do Atlântico, em sua fase negativa, quando há uma anomalia negativa de temperatura na superfície do Atlântico Sul. Isso altera a célula de Hadley e provoca subsidência anômala no Hemisfério Sul (ALVES; et al, 2005). Como resultado, tem-se a permanência da ZCIT por mais tempo no Hemisfério Norte e, consequentemente, há redução dos índices pluviométricos nas regiões Norte e Nordeste do Brasil, como por exemplo, no ano de 2005.

O entendimento físico da variabilidade termodinâmica da atmosfera tropical é de grande importância para a compreensão de tais eventos e estudos sobre isso datam das primeiras décadas do século passado (WALKER; BLISS, 1932).

Além do Dipolo do Atlântico, o El Niño também pode provocar esse tipo de alteração, interferindo nos índices de precipitação. Esse fenômeno é caracterizado pelo aquecimento das águas da porção equatorial do Oceano Pacífico. Possui uma duração de doze a dezoito meses e ocorre com uma periodicidade de dois a sete anos. Nesse caso predominam movimentos de subsidência atmosférica na Região Nordeste do Brasil, inibindo a formação de nuvens por convecção. Isso pode ser explicado pelos movimentos verticais associados à célula de Walker (MELO; CAVALCANTI; SOUZA, 2009). Outros trabalhos demonstram que a precipitação do setor norte do Nordeste do Brasil é diretamente controlada pela variabilidade da atividade convectiva sobre os Oceanos Atlântico e Pacífico Tropicais (MOURA; SHUKLA, 1981; PHILANDER, 1990).

Na literatura científica encontram-se trabalhos que objetivam relacionar a termodinâmica e a atividade convectiva sobre a porção tropical dos oceanos Atlântico e Pacífico com a variabilidade das chuvas no setor norte do Nordeste do Brasil. Como exemplos, pode-se citar o trabalho de Alves et. al. (2005), associando os movimentos verticais das Células de Hadley e Walker com a qualidade da estação chuvosa, ou, ainda, os trabalhos de Moura e Shukla, (1981), Philander (1990) e Alves e Repelli, (1992).

Assim, devido às anomalias de temperatura nos oceanos e à atividade convectiva sobre os mesmos, a área apresentará uma variabilidade anual bastante significativa no que diz respeito à precipitação. As chuvas na área de estudos perfazem a normal 1594,4 mm anuais, segundo as normais do INMET (1996).

Observando a figura 2 com os totais de precipitação anuais no período de 1913 a 2000 é possível observar a existência de significativa variabilidade pluviométrica local, pois alguns anos irão se distanciar significativamente dos valores normais. Segundo Nimer (1977), tal variabilidade no setor setentrional do Nordeste se deve ao fato da dependência quase que exclusiva da atuação da Zona de Convergência Intertropical já mencionada. 
Ao analisar-se valores de precipitação interanual do município de Luis Correia do período de 1913 a 2000, tem-se a média de 1498 milímetros e o desvio padrão anual fica em torno de 822 milímetros. Para os anos com ocorrência do fenômeno El Ninõ, classificados pelo Climate Prediction Center como eventos de forte intensidade, observa-se um índice de precipitação pluviométrica bem abaixo da média estipulada para o período. Assim, podem-se considerar como anos secos os que apresentarem totais pluviométricos inferiores à média menos o desvio padrão. Desta forma, são caracterizados como tal os anos que tiveram precipitação inferior a $676 \mathrm{~mm}$ anuais. Alves et. al. (2005) afirmam que as variações de temperatura observadas nos oceanos tropicais, particularmente na bacia do Pacífico Tropical, são responsáveis por anomalias climáticas em várias áreas do globo, como por exemplo, no setor norte da costa do Nordeste do Brasil.

Como pode ser observado na figura 1 , existe uma variabilidade bastante significativa na distribuição interanual das chuvas, podendo ocorrer anos com mínimas e máximas excepcionais. Variabilidade é a maneira como os parâmetros climáticos oscilam em um determinado período monitorado, pois os dados registrados podem ficar próximos dos valores médios, mas também podem ter resultados superiores ou inferiores aos mesmos (TAVARES, 2004).

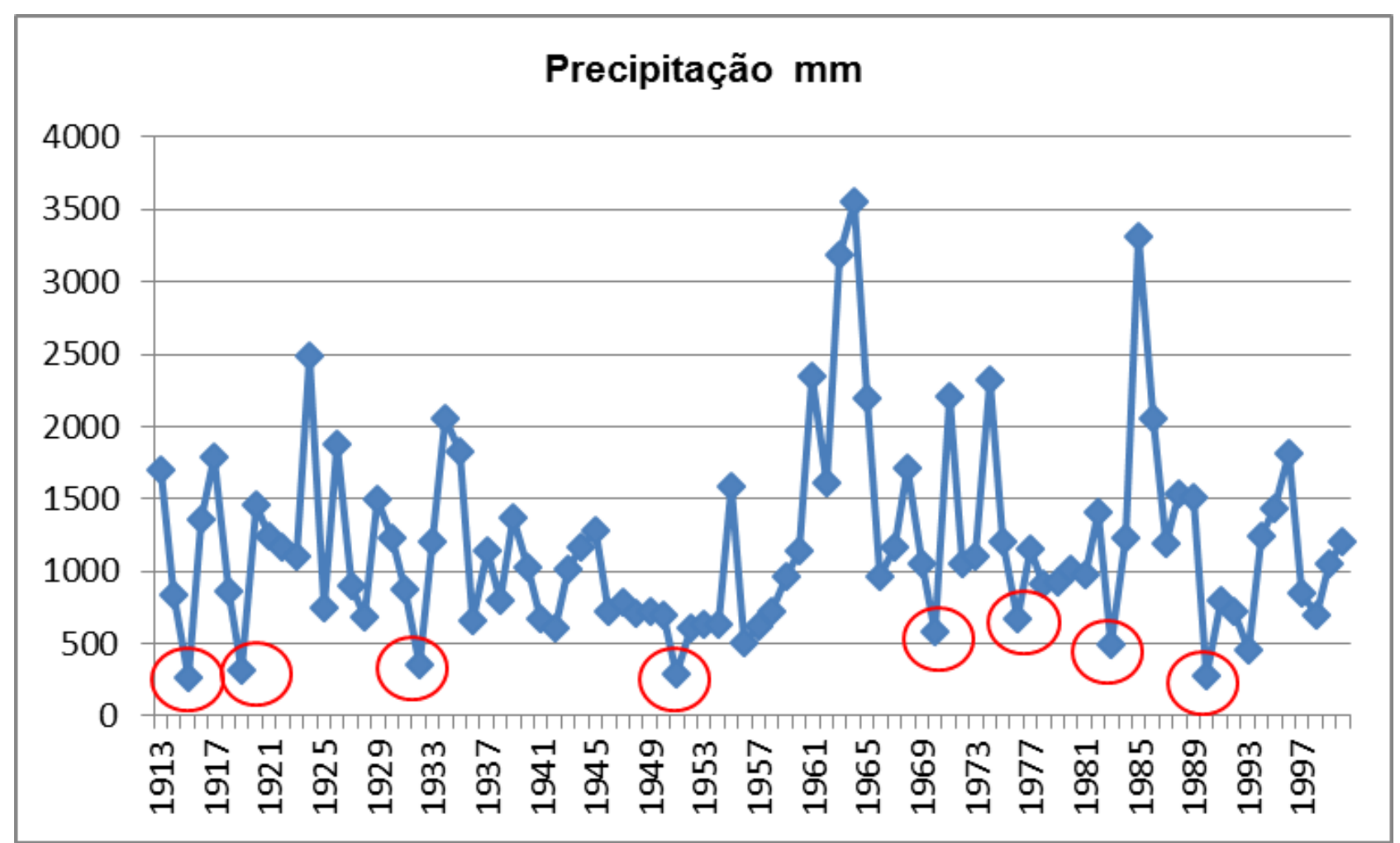

Figura 3: Precipitação anual acumulada, estação Luis Correia, série histórica de 1913 a 2000. Fonte: Lima (2005).

Dentro do intervalo temporal apresentado pela figura 1, observa-se que os maiores valores foram registrados no ano de 1964, com 3554 mm, e em 1985, com 3311 mm. Pode-se notar ainda, através desta figura, que os anos com desvios negativos ocorreram com maior frequência do que os 
anos com desvios positivos. Eles aconteceram no período por dezenove vezes, com maior frequência entre os anos de 1951 e 1956, quando ocorreram cinco anos com precipitação bem aquém da média. Os desvios negativos ocorreram, entre 1913 e 2000, com uma periodicidade média de 4,5 anos, com intervalos máximos de 13 anos e mínimos de 1 (um) ano. Assim, pode-se perceber que não há uma periodicidade regular na distribuição do fenômeno. Desta forma, faz-se necessária sua previsão na tentativa de amenizar seus efeitos socioeconômicos.

Os anos com desvios positivos ocorreram dez vezes durante o período monitorado, com intervalo médio entre os eventos de 6,5 anos, e com intervalo maior de 27 anos.

Ao observar os valores mensais é possível perceber que os eventos chuvosos ocorridos entre os meses de agosto a novembro são esporádicos e com valores inexpressivos.

Os meses com maior precipitação ocorrem no primeiro semestre do ano, de janeiro a junho, perfazendo um total de aproximadamente $94 \%$ do total anual, com máximas mensais em março e abril de $371 \mathrm{~mm}$ e $405 \mathrm{~mm}$, respectivamente, como se pode observar na figura 3, com as médias mensais no período de 1961 a 1990 e divulgadas pelo INMET (1996). Os meses de agosto a novembro caracterizam o período de estiagem.

\subsection{Comportamento da atmosfera no período 2010 - 2014}

Dada a maior frequência dos desvios negativos de precipitação pluviométrica, optou-se aqui por usar o recorte temporal de 5 anos $(2010$ - 2014), visto que os desvios negativos ocorreram repetidas vezes nesse intervalo, como em 2010, ano com precipitação total de 637,9 mm, praticamente metade do valor normal. Em 2011 foram registrados 1017,1 mm, valor um pouco abaixo da normal. Em 2012 foram 624,8 mm, outro ano com valor bem aquém do esperado. 853,2 mm em 2013 e 978,8 mm em 2014. São cinco anos conseguintes com precipitação abaixo da normal aproximada de $1594,4 \mathrm{~mm}$.

Em função disso, a vazão dos rios da região, que é dependente do regime de precipitação, torna-se menor, reduzindo consequentemente a competência dos mesmos em transportar matéria. Dessa forma, a quantidade de sedimentos de origem continental que chega ao litoral tende a ser menor.

A umidade tende a ser diretamente proporcional aos valores de precipitação. Assim, os maiores valores médios mensais de umidade relativa registrados no período de 2010 a 2014, foram em 2011, com média anual de 70,52\%, valor médio máximo registrado em abril, com 84,12\%, e mínimo de 58,32\%, em setembro. Em 2012 a média anual foi de 64,06\%. O valor médio máximo registrado em março foi de $79,55 \%$, e o mínimo de $56,10 \%$, em outubro. 
Já a evaporação possui um comportamento inversamente proporcional ao da precipitação. Assim, os valores de evaporação foram maiores no período seco de 2012, quando o total anual alcançou 1946,1 mm, com máximo mensal registrado em outubro de 225,9 mm. Já os menores valores registrados ocorreram no ano mais chuvoso do período (2011), com total anual de 1400,7 mm e máximo mensal de $214,1 \mathrm{~mm}$ em dezembro (figura 4).

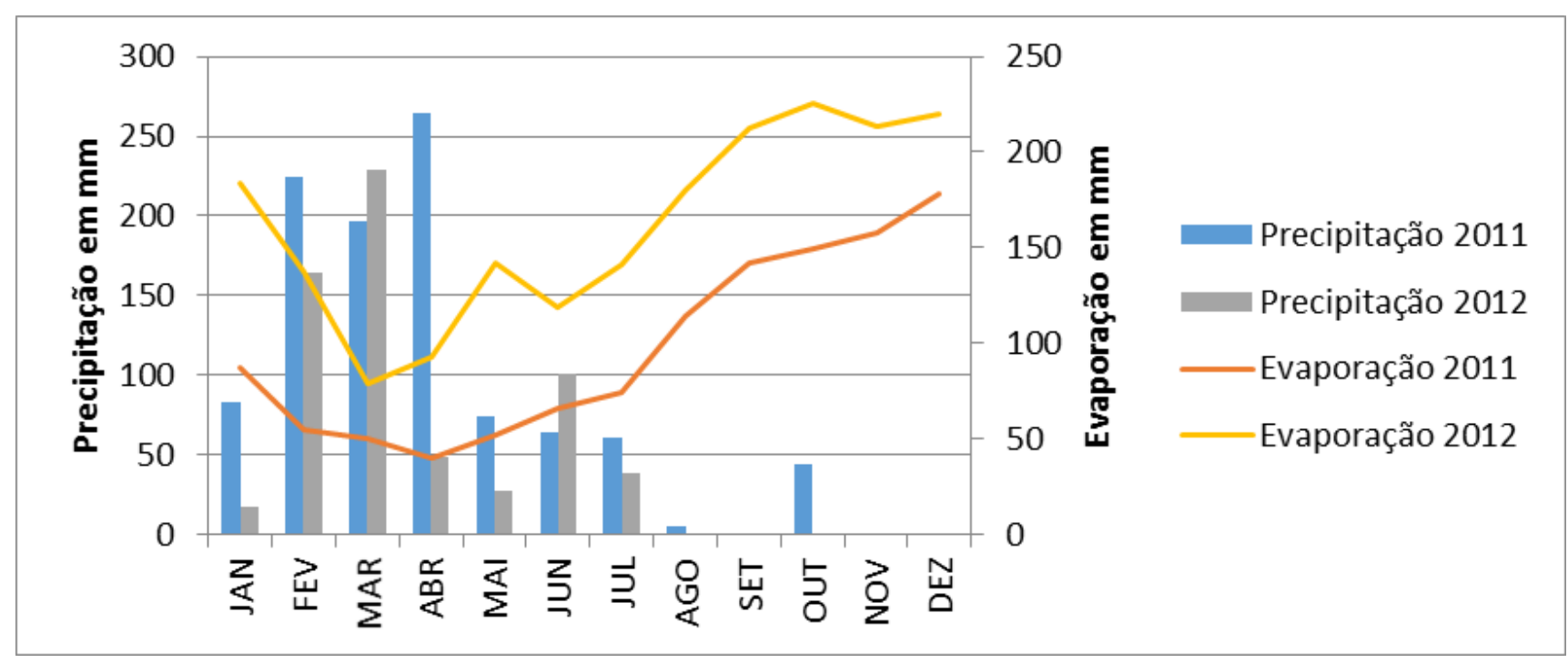

Figura 4 : Precipitação e evaporação mensal em mm na estação Parnaíba no ano de 2011 e 2012

Fonte: Instituto Nacional... [2011]

A umidade relativa do ar tende a acompanhar as variações de precipitação. Maiores valores de umidade relativa diminuem a evaporação, deixando as areias umedecidas, o que controla diretamente a eficiência do transporte eólico, visto que a umidade aumenta significativamente a coesão entre os grãos de areia, exigindo uma maior energia proveniente da ação dos ventos para sua efetiva movimentação. Assim, durante o período de estiagem, especialmente entre os meses de agosto a novembro, a atividade eólica é intensificada devido à redução dos índices de umidade.

A umidade máxima é registrada no mês de março, com um valor de $84 \%$, e o valor mínimo em setembro com 68,8\%. A partir do mês de março, os valores apresentam uma curva descendente, atingindo os valores mínimos mensais entre os meses de setembro a novembro. Nesse período o transporte eólico é intensificado ocorrendo maior acúmulo de sedimentos na pós-praia e dunas. Ao plotar a umidade relativa e evaporação em um mesmo gráfico observa-se uma razão inversamente proporcional, visto que evaporações acentuadas ocorrem durante os períodos com menor umidade relativa do ar, como se pode observar na figura 5. 


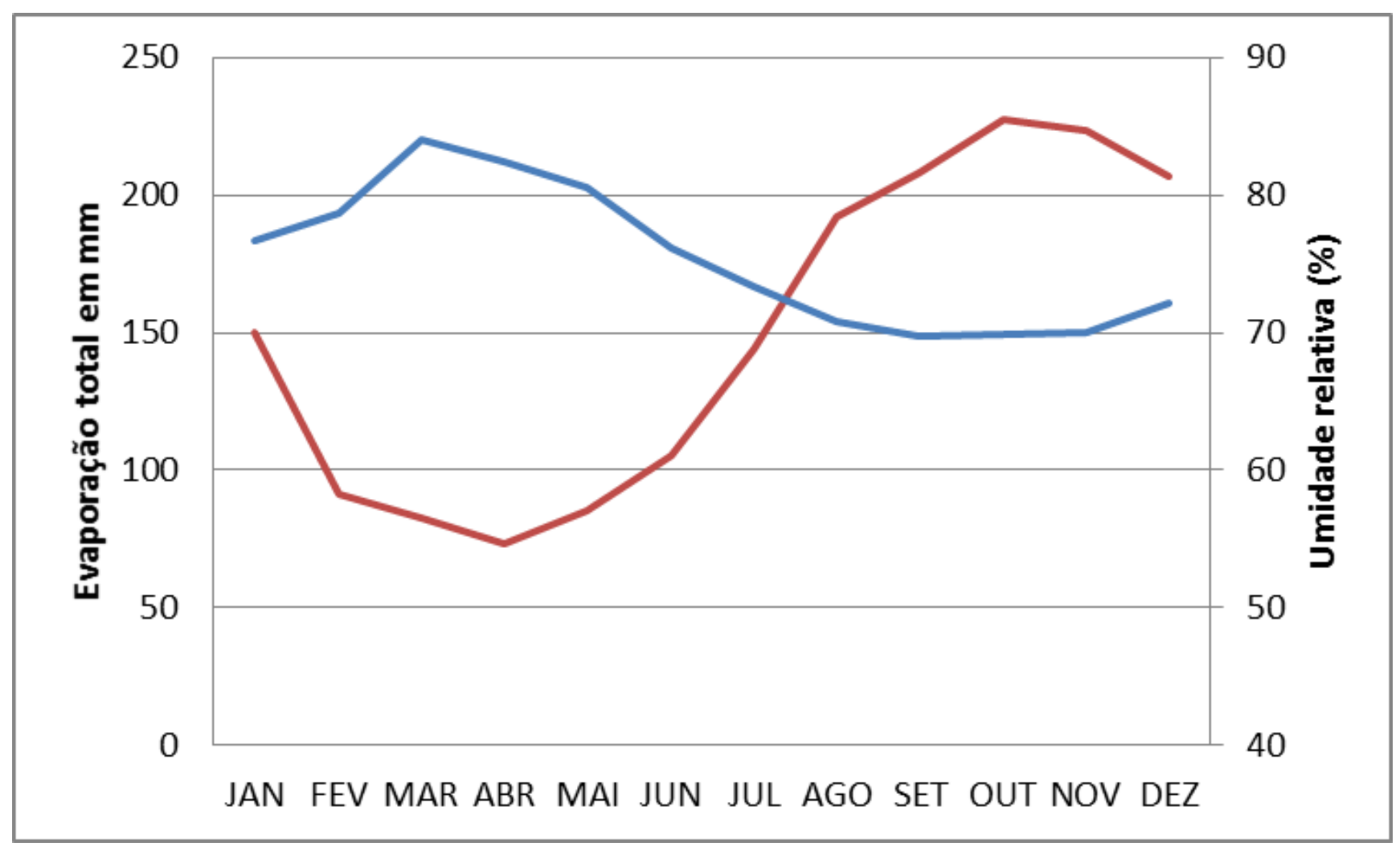

Umidade Relativa do ar $(\%)$

Evaporação total (mm)

Figura 5 :Umidade relativa do ar média para o período de 1978 a 1987. Fonte: Empresa... (1990)

No contexto atmosférico os ventos vão ser um importante elemento de controle da evolução morfossedimentar do litoral, pois agem diretamente e de forma seletiva no transporte de sedimentos através dos processos de deflação eólicos, dando origem a feições marcantes na costa, como os campos de dunas. Em função de sua ação seletiva, geralmente os depósitos eólicos apresentam-se bem selecionados.

Os ventos também irão interferir diretamente nos processos oceanográficos, como por exemplo, na formação e atuação do regime de ondas locais, alterando sua capacidade em mobilizar sedimentos da face de praia. As baixas latitudes no hemisfério sul são dominadas, de maneira geral, por ventos de leste - os alísios, além da ação em menor escala das brisas.

Paula (2013), analisando dados de velocidade média do período 1990 a 2010, de Parnaíba, observou tendência de redução da velocidade média dos ventos, fato que pode ser explicado pelo aumento de estruturas construídas na região e consequentemente no aumento do atrito do vento com as mesmas. No entanto, ao observar dados da estação Parnaíba do INMET, de 2010 a 2014, verifica-se uma tendência ao aumento progressivo da velocidade dos ventos (figura 6).

Outra tendência que se observa é a predominância de maiores velocidades no período de estiagem, que crescem em direção aos meses finais do ano (figura 7), fato observado por Bittencourt et al. (1990) e relatado nesse trabalho. Os maiores registros são verificados nos meses 
de outubro a dezembro, com valores médios mensais variando entre 4,00 a 5,81 m/s. Já os menores ocorrem entre os meses de abril e julho com velocidades que oscilam entre $1,76 \mathrm{~m} / \mathrm{s} \mathrm{e} \mathrm{3,4} \mathrm{m/s.}$

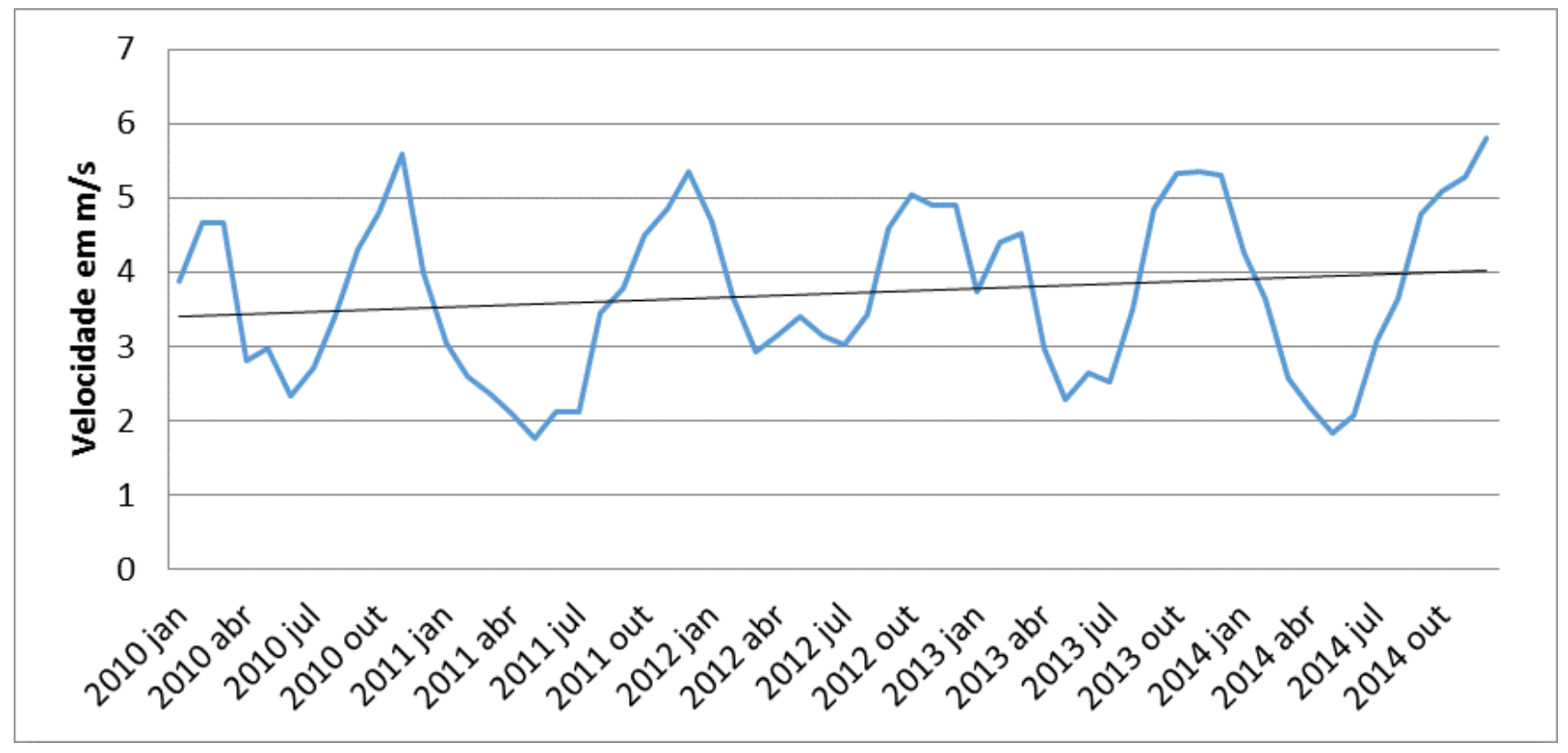

Figura 6 : Tendência da velocidade média dos ventos no período 2010 - 2014

Fonte: Instituto Nacional... [2011]

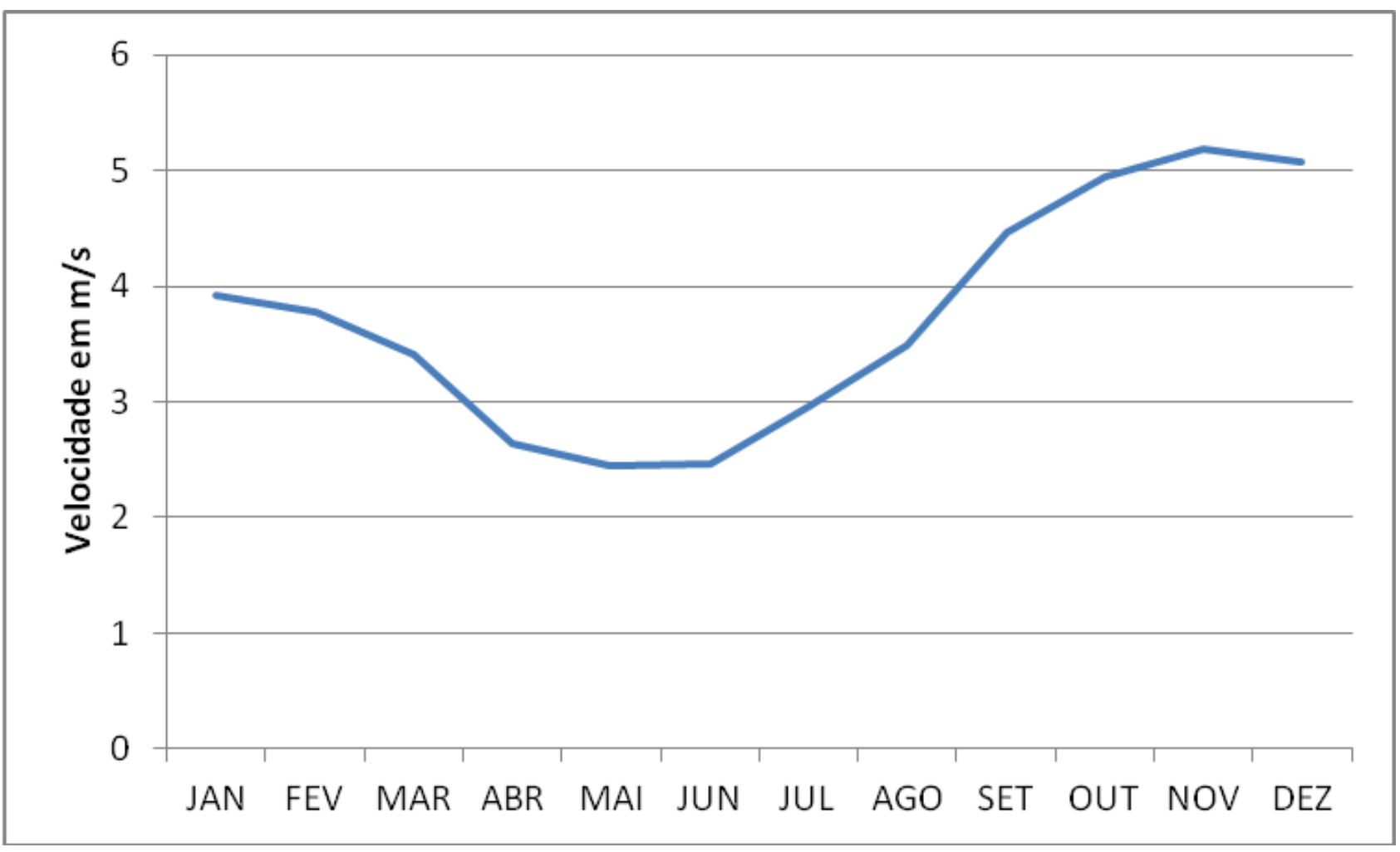

Figura 7: Comportamento sazonal da velocidade média dos ventos no período 2010 - 2014

Fonte: Instituto Nacional.... [2011] 
O acréscimo de velocidade é verificado no período de estiagem, quando a carga de sedimentos continentais é ainda mais reduzida devido à diminuição da vazão dos cursos fluviais. Isso, aliado à redução da umidade relativa do ar, potencializa os efeitos do transporte eólico da faixa de praia para a zona de pós-praia. Além do que, ventos de maior intensidade favorecem a gênese de ondas com maior energia e, consequentemente, com maior capacidade de transporte.

O comportamento do agente eólico na área de estudos assemelha-se ao de outros trechos do litoral Norte do Nordeste, como no estado do Ceará, onde se verificam máximas nos períodos de estiagem e mínimas no período chuvoso (MUEHE, 2006a). Os valores médios de velocidade apresentam comportamento decrescente no primeiro semestre, de janeiro a junho. A partir daí, apresenta valores crescentes até novembro, quando se registram as maiores velocidades. Além disso, as médias mensais assemelham-se aos encontrados por Paula (2013), no litoral do Piauí, variando de 3 a $8,5 \mathrm{~m} / \mathrm{s}$.

No Maranhão, as maiores velocidades ocorrem nos meses mais secos, como em outubro, conforme Feitosa (1996). No litoral cearense, na cidade de Cascavel, segundo Morais et al. (2004), as velocidades máximas são registradas de julho a novembro, com valores de $7-11 \mathrm{~m} / \mathrm{s}$, e as mínimas, no período chuvoso, com valores médios de $3,5 \mathrm{~m} / \mathrm{s}$.

Analisando as velocidades médias diárias dos ventos no período de 2010 a 2014, observa-se que os menores valores foram registrados no mês de maio de 2014 , com mínima diária de $0,43 \mathrm{~m} / \mathrm{s}$, verificada no dia 13 do referido mês. Já as velocidades máximas diárias dos ventos deste período foram registradas no mês de novembro de 2013, com valor de 7,35 m/s, verificado no dia 16 do referido mês. Paula (2013) verificou de forma experimental, nos meses de maio e agosto de 2011, velocidades que oscilaram entre 2,3 e $9,2 \mathrm{~m} / \mathrm{s}$.

Em relação à direção há uma predominância de ventos que variam de NE e E, especialmente nos meses de Agosto a Dezembro, (BITTENCOURT et al., 1990). Paula (2013), verificou a presença de ventos oriundos do quadrante $1\left(0-90^{\circ}\right)$.

Tal conjuntura favorece a movimentação de areia da face de praia, especialmente do estirâncio, quando descoberto em ocasião das baixa-mares, em direção aos campos de dunas frontais. Esse processo é intensificado no período de estiagem quando os ventos assumem maior capacidade energética, registrando maiores velocidades. Associado a isso, o período seco também apresenta menores valores de umidade relativa do ar e maiores taxas de evaporação, potencializando o transporte eólico.

Além da movimentação sedimentar da faixa de praia em direção aos campos de dunas, há um continuo deslocamento dessas dunas, predominantemente móveis, em direção ao interior do continente. 
Os sedimentos depositados nos campos de dunas, dificilmente retornarão à face de praia (considerando a direção predominante em que são movimentados), a não ser que atinjam os cursos fluviais e sejam novamente trazidos à linha de costa .

Além da umidade e evaporação, a velocidade dos ventos também se mostrou influenciada pelas taxas de precipitação, visto que os menores valores de velocidade do agente eólico são verificados no ano de 2011, justamente o mais chuvoso dos últimos cinco anos.

Percebem-se, em relação à atmosfera, dois cenários sazonais bem marcados. Um chuvoso, no primeiro semestre do ano, marcado por maiores taxas de umidade, menor evaporação e velocidades do vento mais amenas. Essa conjuntura favorece a maior entrada de sedimentos continentais na praia através dos cursos fluviais, e uma menor movimentação dos mesmos, em virtude da maior umidade e menor evaporação, que garantem certo grau de coesão aos sedimentos do estirâncio. Isto dificulta a movimentação dos mesmos em direção ao continente por efeito dos ventos. O outro cenário é verificado no segundo semestre, com menores taxas de umidade e maior evaporação e velocidade de ventos, o que, por sua vez, favorece o transporte eólico. Além dos cenários sazonais, pode-se concluir que a variação interanual de precipitação irá influenciar a movimentação sedimentar, intensificando o transporte de sedimentos da praia para o continente nos anos mais secos e atenuando-o nos anos mais chuvosos.

Como consequência aos anos seguidos com desvios negativos de precipitação, esperase, em geral, verificar maior amplitude granulométrica nos sedimentos coletados e analisados entre as estações seca e na chuvosa. No entanto, fatores locais como forma da linha de costa, presença de elementos estabilizadores naturais e artificiais, proximidade a cursos fluviais, nível de exposição ao efeito das ondas e ângulo de incidência das mesmas, irão influenciar os resultados.

\subsection{Análise dos Sedimentos de Praia}

No perfil 1 o diâmetro dos sedimentos no período chuvoso para a antepraia, estirâncio e pós-praia em phi $[\phi]$ foi, respectivamente, 0,116 (areia grossa) para a antepraia, -0,074 phi $[\phi]]$ (areia muito grossa) para o estirâncio e 2,123 phi $[\phi]$ (areia fina) para a pós-praia. Já no período

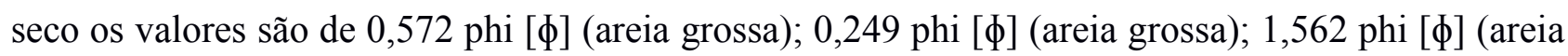
média).

Os valores granulométricos não demonstraram comportamento sazonal, no entanto variaram, mostrando um calibre ligeiramente maior no período chuvoso para antepraia e estirâncio, o que é pouco comum, visto que os agentes atmosféricos e oceanográficos demonstram maior poder de atuação no período de estiagem, quando se registram ventos mais fortes, ondas de maior energia e menor umidade do ar - conjuntura que favorece a retirada de fragmentos menores e torna o 
diâmetro médio dos sedimentos maior. Além do que, há na estação seca um menor input de sedimentos fluviais por conta da redução da descarga fluvial, em decorrência da redução da precipitação.

O selecionamento realizado através dos valores do desvio padrão gráfico variou de moderado a bem selecionado. Para Suguio (2003), a redução do tamanho do grão ocorre com o aumento da seleção, o que pode sugerir que grãos de maior calibre com algum grau de selecionamento sejam incomuns, no entanto, Muehe, (2011) afirma que ocorre seleção em áreas fontes de sedimentos associada a sedimentos mais grossos.

Isso se dá devido à competência dos agentes dinâmicos em movimentar as frações de areia de menor calibre (areia fina a areia muito fina) como pode ser percebido no histograma de frequência a seguir (figura 8), no qual se verifica a ausência de silte e argila, além de uma ocorrência pouco significativa de areia muito fina e areia fina, com maior frequência de frações compreendidas entre os valores no intervalo de -2 a 1 phi $[\phi]$, caracterizando sedimentos que vão de areia muito grossa a areia média.

Frequência \%

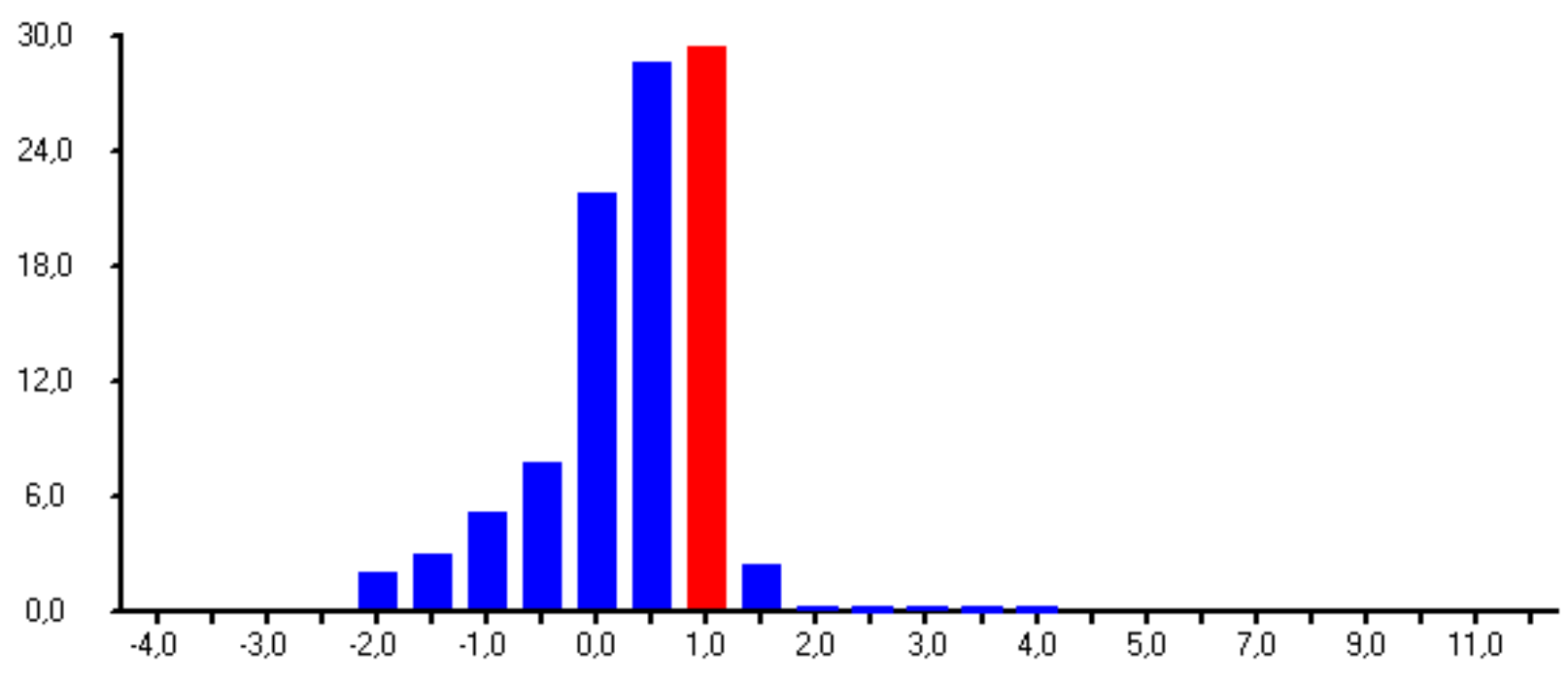

Figura 8: Histograma de frequência perfil 1 (antepraia período chuvoso).

Fonte: Organizada pelo autor. Amostra coletada em março de 2014 e tratada no Laboratório de Geologia e Geomorfologia Costeira e Oceânica (LGCO) da Universidade Estadual do Ceará (UECE)

Os valores do desvio padrão gráfico $(\square \mathrm{I})$ para o perfil 1 variam de 0,583 a 0,744 na antepraia, denotando seleção moderada das partículas, sendo ligeiramente melhor no período chuvoso. No estirâncio, os valores variam de 0,458 a 0,485, sendo bem selecionados, mas também com seleção ligeiramente melhor no período chuvoso. Na faixa de pós-praia os valores variam de 0,642 a 0,754, apresentando grãos moderadamente selecionados. Os valores de seleção 
acompanharam a variação do diâmetro médio dos sedimentos, apresentando maior dispersão dos valores no período de estiagem e melhorando o selecionamento no período chuvoso, quando o diâmetro médio também é um pouco maior.

Em relação à assimetria (skl), os valores de distribuição foram negativos, inclinando-se para as frações mais grosseiras, variando de $-0,284$ a -0,134. A exceção se deu com os valores da póspraia, que apresentaram uma assimetria muito positiva, com resultado de 0,788 , inclinando-se para as frações mais finas de sedimentos (a direita do valor modal), e da antepraia, no período de estiagem, que apresentou distribuição aproximadamente simétrica com valor de -0,097.

O perfil 2 apresentou comportamento similar ao 1, com predominância de maiores calibres granulométricos nos compartimentos de antepraia e estirâncio, classificados como areia muito grossa. No caso da pós-praia há predominância de areias médias. Os valores médios encontrados no período chuvoso e de estiagem foram respectivamente de -0,411 e - 0,533 phi $[\phi]$ na antepraia, 0,687 e $-0,691$ phi $[\phi]$ no estirâncio e 1,598 e 1,625 phi $[\phi]$ na pós-praia.

Apesar de também não demonstrar comportamento sazonal de forma perceptível, o calibre dos sedimentos foi ligeiramente maior no período de estiagem, acompanhando as mudanças sazonais ocorridas na atmosfera e no oceano. Esse resultado é diferente do apresentado pelo perfil 1. Outra diferença considerável é que o calibre médio é maior no perfil 2 do que no anterior.

No perfil 2 os sedimentos variaram de mal selecionados a moderadamente selecionados, com valores de desvio padrão gráfico $(\square \mathrm{I})$ que oscilaram de 0,761 a 1,055 na antepraia, de 0, 615 a 0,754 no estirâncio e de 0,815 a 0,869 na pós-praia.

A assimetria (skl) predominantemente negativa caracteriza o perfil 2. A exceção se dá no compartimento de pós-praia, que apresenta assimetria positiva em ambas as estações. Os valores de assimetria variam de $-0,143$ a $-0,139$ (negativa) para a antepraia, de $-0,154$ a $-0,112$ (negativa) no estirâncio e de 0,242 a 0,255 na pós-praia (positiva).

Dessa forma, a faixa de praia propriamente dita, devido à alta energia dos agentes oceanográficos, principalmente, possui uma distribuição que tende às frações de maior calibre, como se pode observar na figura 9.

O maior calibre de sedimentos encontrados nos perfis 1 e 2 é indicativo de alta energia dos agentes atuantes no transporte sedimentar, bem como é um indício de que a praia de Macapá funciona como área fonte de sedimentos para as praias localizadas à jusante da corrente longitudinal (oeste). Pode ser também interpretado como um indício de vulnerabilidade à erosão costeira. Nesse caso não há correlação positiva entre o comportamento da atmosfera e a dinâmica sedimentar. 
Frequência \%

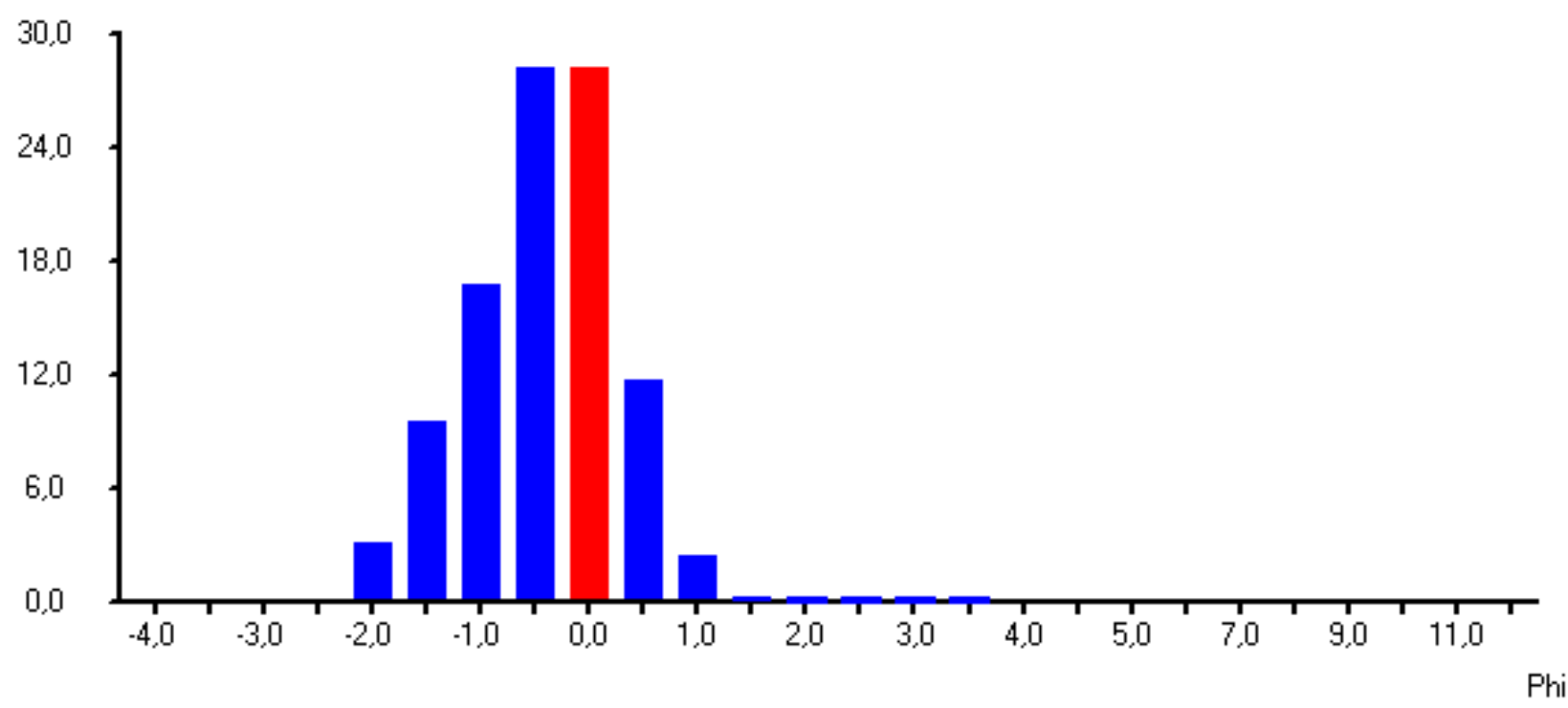

Figura 9: Histograma de frequência ponto 2 (antepraia, período chuvoso)

Fonte: Organizada pelo autor. Amostra coletada em março de 2014 e tratada no Laboratório de Geologia e Geomorfologia Costeira e Oceânica (LGCO) da Universidade Estadual do Ceará (UECE)

O perfil 3, localizado na porção leste da praia de Maramar, é o que demonstra comportamento sazonal mais evidente na distribuição granulométrica. No período chuvoso o diâmetro médio dos grãos é reduzido de forma significativa, acompanhando o comportamento dos agentes atmosféricos e oceanográficos que favorecem uma menor movimentação de sedimentos. Durante a estiagem, a maior energia dos ventos e ondas favorece uma maior movimentação de sedimentos, em especial as areias de menor diâmetro. Boa parte das frações mais finas de areia é movimentada pelos ventos em direção à pós-praia, resultado semelhante ao encontrado por Bittencourt et al. (1990), na praia de Atalaia, em Luís Correia. A amplitude sazonal no diâmetro é intensificada em virtude dos desvios negativos de precipitação.

Dessa forma, a classificação pelo diâmetro médio em phi $[\phi]$ para o referido perfil varia de 0,365 (areia grossa) a 2,980 (areia fina) na antepraia, de 0,619 (areia grossa) a 2,326 (areia fina) no estirâncio, e de 0,930 (areia grossa) a 2,021 (areia fina) na pós-praia, respectivamente, nos períodos de estiagem e chuvoso.

A presença de subpopulação mais grossa na pós-praia indica a ação de agentes de maior energia, nesse caso, agentes oceanográficos que, em condições excepcionais de tempestade, ampliam sua área de atuação, indo além da zona intertidal (estirâncio).

O selecionamento de partículas no perfil 3 variou de moderado a muito bem selecionado, com valores de desvio padrão gráfico $(\square \mathrm{I})$ entre 0,318 e 0,954 . Os valores encontrados para o período chuvoso e de estiagem foram respectivamente de 0,318 (muito bem selecionada) e 0,744 (moderadamente selecionado) na antepraia, 0,616 (moderadamente selecionado) e 0,851 
(moderadamente selecionado) no estirâncio e 0,610 (moderadamente selecionado) e 0,954 (moderadamente selecionado) na pós-praia. O selecionamento foi melhor durante a estação chuvosa com a entrada de partículas finas na praia.

Os valores de assimetria (skl) mostraram-se mais positivos durante o período de estiagem, com valores entre 0,041 e 0,307 , variando de aproximadamente simétrico a muito positivo. No período chuvoso os valores de assimetria foram negativos, variando de muito negativa a negativa, com valores entre -0,041 e -0,307. Apesar da redução do calibre médio devido a maior presença de sedimentos finos, a frequência de partículas maiores continua sendo bastante significativa, fazendo com que a curva de distribuição incline-se para o lado esquerdo do valor modal. A frequência de distribuição granulométrica do perfil 3 é exemplificada na figura 20.

\section{Frequência \%}

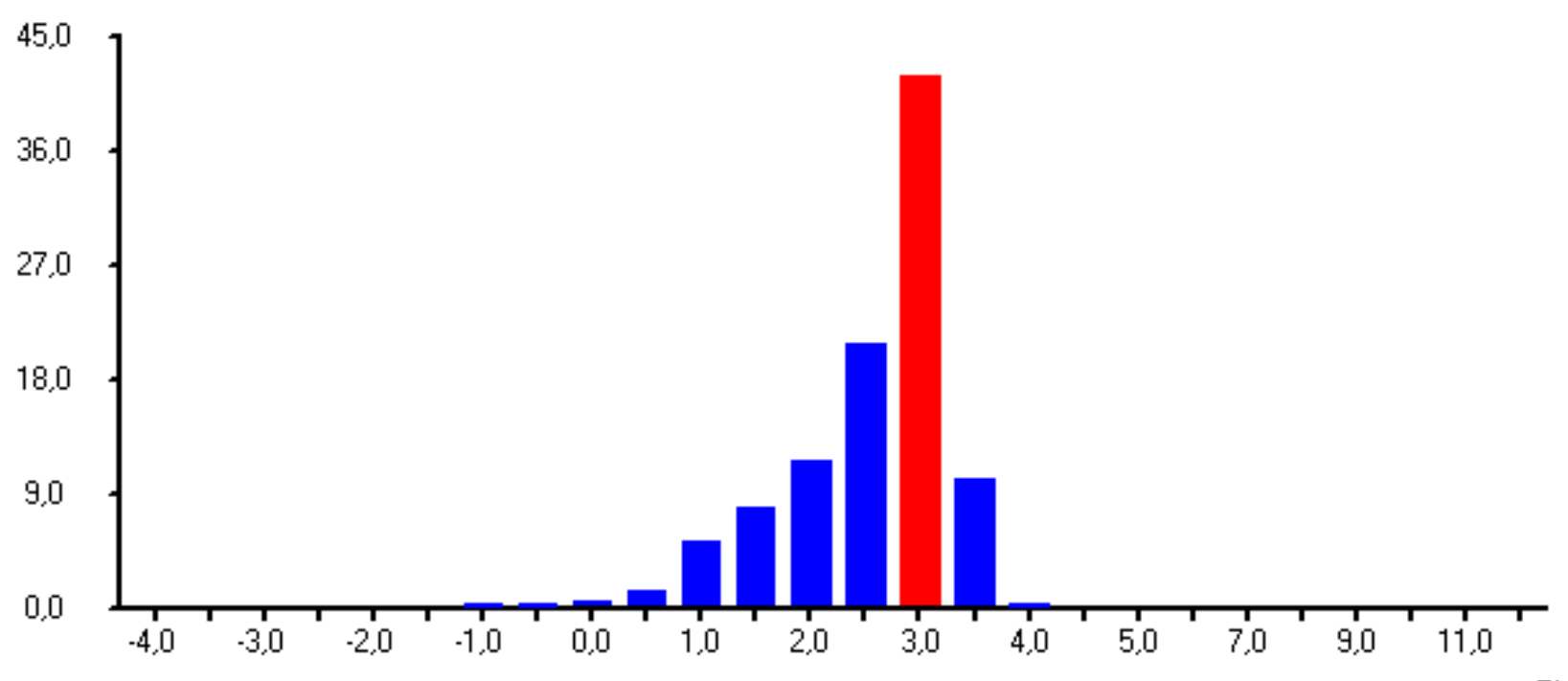

Figura 10: Histograma de frequência do perfil 3 (estirâncio, período chuvoso)

Fonte: Organizada pelo autor. Amostra coletada em março de 2014 e tratada no Laboratório de Geologia e Geomorfologia Costeira e Oceânica (LGCO) da Universidade Estadual do Ceará (UECE)

No perfil 4, a oeste do anterior, localizado na porção central da praia de Maramar, a classificação das areias variou de areia fina a areia média, com valores de diâmetro médio entre $1,578$ e 2,793 phi [ $\phi]$. O calibre médio dos sedimentos apresentou também comportamento sazonal, mas não de forma tão evidente quanto no perfil 3. Percebeu-se uma redução na frequência de sedimentos de menor diâmetro no período de estiagem e consequentemente aumento do calibre médio.

Os valores médios encontrados no período chuvoso e de estiagem foram, respectivamente, de 2,793 e 2,438 phi [ $\phi]$ na antepraia, classificados como areia fina; de 2,252 e 1,763 phi [ $[$ ], 
classificados como areia fina e areia média, no estirâncio. Já na pós-praia, de 1,677 e 1,578 phi [\$], classificados como areia média.

A seleção de partículas varia de moderada a bem selecionada, com valores de desvio padrão gráficos $(\square \mathrm{I})$ situados entre 0,492 e 0,861, registrados no compartimento de antepraia, durante a estação chuvosa e seca, respectivamente. No estirâncio, os valores encontrados foram de 0,734 e 0,765; na pós-praia, de 0,619 a 0,627.

A assimetria mostrou-se muito negativa nas áreas de maior influência oceânica (antepraia e estirâncio). Mesmo com a redução do calibre e melhor selecionamento, a frequência de clastos continua tendendo às frações de maior diâmetro, como se pode observar na figura 11. Já na faixa de pós-praia variou de simétrica a assimétrica positiva.

\section{Frequência \%}

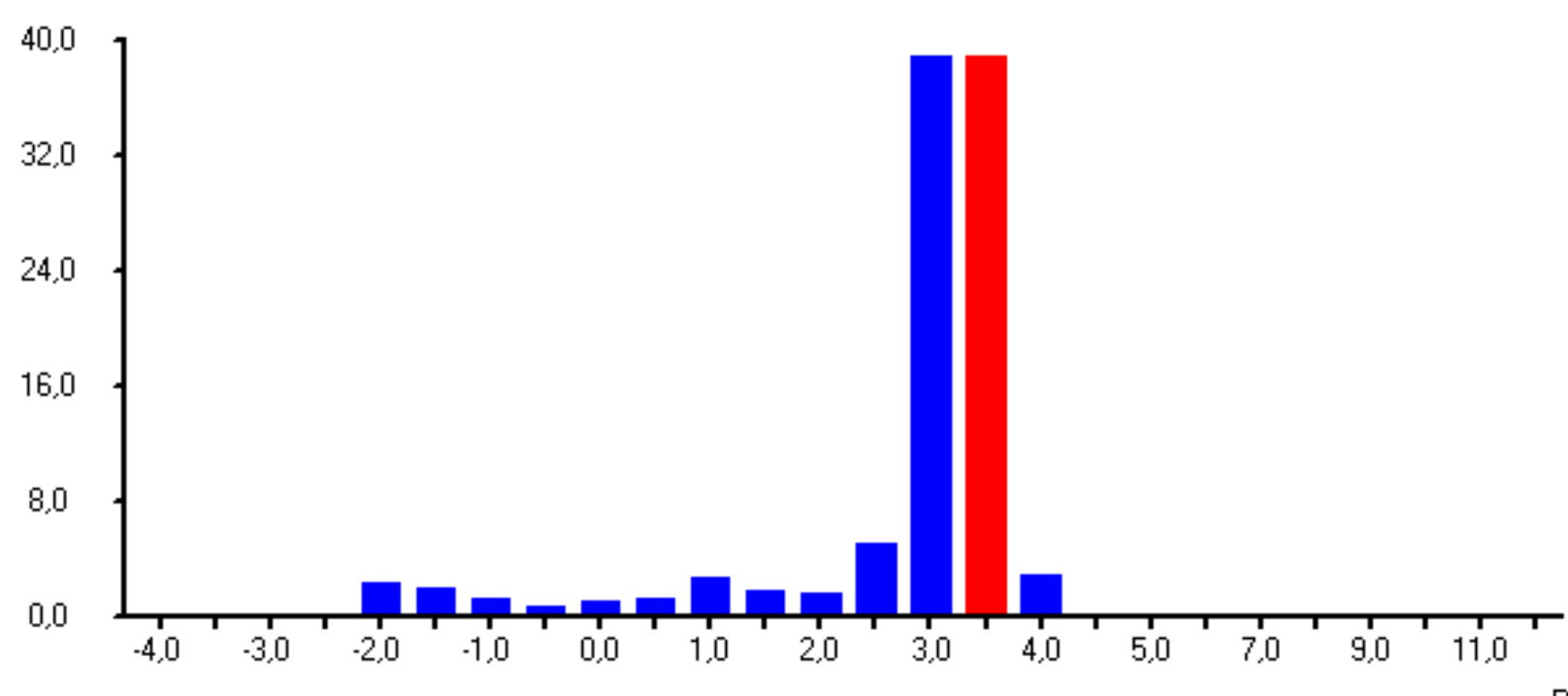

Figura 11: Histograma de frequência perfil 4 (antepraia, período chuvoso).

Fonte: Organizado pelo autor. Amostra coletada em março de 2014 e tratada no Laboratório de Geologia e Geomorfologia Costeira e Oceânica (LGCO) da Universidade Estadual do Ceará (UECE).

No perfil 5 os sedimentos variaram de areia fina a areia média, com calibres médios entre $1,234$ e 2,132 phi [ $\phi]$. Esse ponto está localizado no extremo oeste da praia de Maramar e apresenta redução sensível do calibre médio em relação aos demais, denotando redução significativa da energia dos agentes dinâmicos, o que permite a permanência de areias de menores diâmetros.

Dessa forma os calibres médios em phi $[\phi]$ encontrados no ponto 5 , nos períodos chuvoso e de estiagem, respectivamente, são de 2,079 (areia fina) e 1,234 (areia média) na antepraia; de 2,132 (areia fina) e 1,481 (areia média) no estirâncio; de 1,945 (areia média) e 1,354 (areia média) na póspraia. A exemplo do ponto 3 há um comportamento sazonal bem marcado, evidenciado pelo 
aumento de calibre médio das partículas sedimentares no período seco, respondendo às mudanças atmosféricas e oceanográficas que intensificam sua ação no segundo semestre do ano.

Em relação ao selecionamento das areias houve variação de moderada a mal selecionada, com valores de desvio padrão gráficos $(\square \mathrm{I})$ entre 0,656 e 1,495, verificados no período chuvoso, respectivamente nos compartimentos de pós-praia e antepraia.

$\mathrm{Na}$ antepraia a seleção de sedimentos foi melhor no período de estiagem, com valor de 0,988 (moderadamente selecionada) e 1,495 (mal selecionada) no chuvoso. No estirâncio não foi verificada variação significativa. Em ambas as estações as areias apresentaram selecionamento moderado com valores de 0,905 no período chuvoso e 0,936 no período de estiagem. No compartimento de pós-praia, a seleção foi melhor no período chuvoso, com valores de 0,656 , e 1,101 no período seco. Esse comportamento da pós-praia é característico da maioria dos perfis e evidencia a redução de energia do transporte eólico no período chuvoso, transportando partículas de menor intervalo granulométrico e, consequentemente, melhorando a seleção de areias.

No que se refere à distribuição granulométrica das amostras do perfil 5, ocorrem compartimentos com assimetria positiva, mesmo em áreas de influência marinha, tanto no período chuvoso quanto no período de estiagem. Distribuições assimétricas positivas são pouco comuns em costas expostas à ação direta das ondas, que possuem uma capacidade significativa de movimentação de partículas. A assimetria positiva está associada à maior ocorrência de areias médias, que ocorre no período chuvoso no compartimento de antepraia e no período seco no estirâncio. Já a maior ocorrência de areias de menor calibre resultou em distribuição assimétrica muito negativa, como se pode observar no histograma de frequência (figura 12).

Os valores de assimetria ( $\mathrm{Skl}$ ) para o período chuvoso e de estiagem são respectivamente de 0,242 e -0,515 (muito negativa) na antepraia; -0,533 (muito negativa) e 0,200 (positiva) no estirâncio; -0,103 (negativa) e -0,085 (simétrica) na pós-praia. A síntese das variáveis estatísticas usadas para na análise dos sedimentos é mostrada na tabela 5.1. Dessa forma, alguns perfis apresentam mudanças sazonais no calibre médio dos sedimentos, uns de forma mais perceptível, como no 3, onde a areia fina é alterada para areia grossa, e outros com modificações menores como no perfil 2.

No que se refere ao calibre, há uma redução significativa desse parâmetro de leste para oeste. Dessa forma, os sedimentos mostraram calibre médio maior nos perfis 1 e 2 . Os resultados da análise granulométrica sugerem tendência a retrogradação da linha de costa na praia de Macapá, verificada em outros trabalhos como os de Rocha (2015). Esses resultados demonstram que esse fragmento costeiro está submetido a agentes de energia significativa e, consequentemente, mais competentes em movimentar as partículas arenosas da face de praia. Dessa forma, o intervalo granulométrico que permanece nesse fragmento de costa é pequeno, correspondente às frações de 
maior calibre, com um selecionamento de partículas que varia de moderado a bem selecionado. $\mathrm{O}$ comportamento do calibre nesses perfis não acompanha as variações sazonais da atmosfera, evidenciando a importância de fatores locais na dinâmica sedimentar. Nesse caso, a correlação atmosfera e dinâmica de sedimentos é negativa.

\section{Frequência \%}

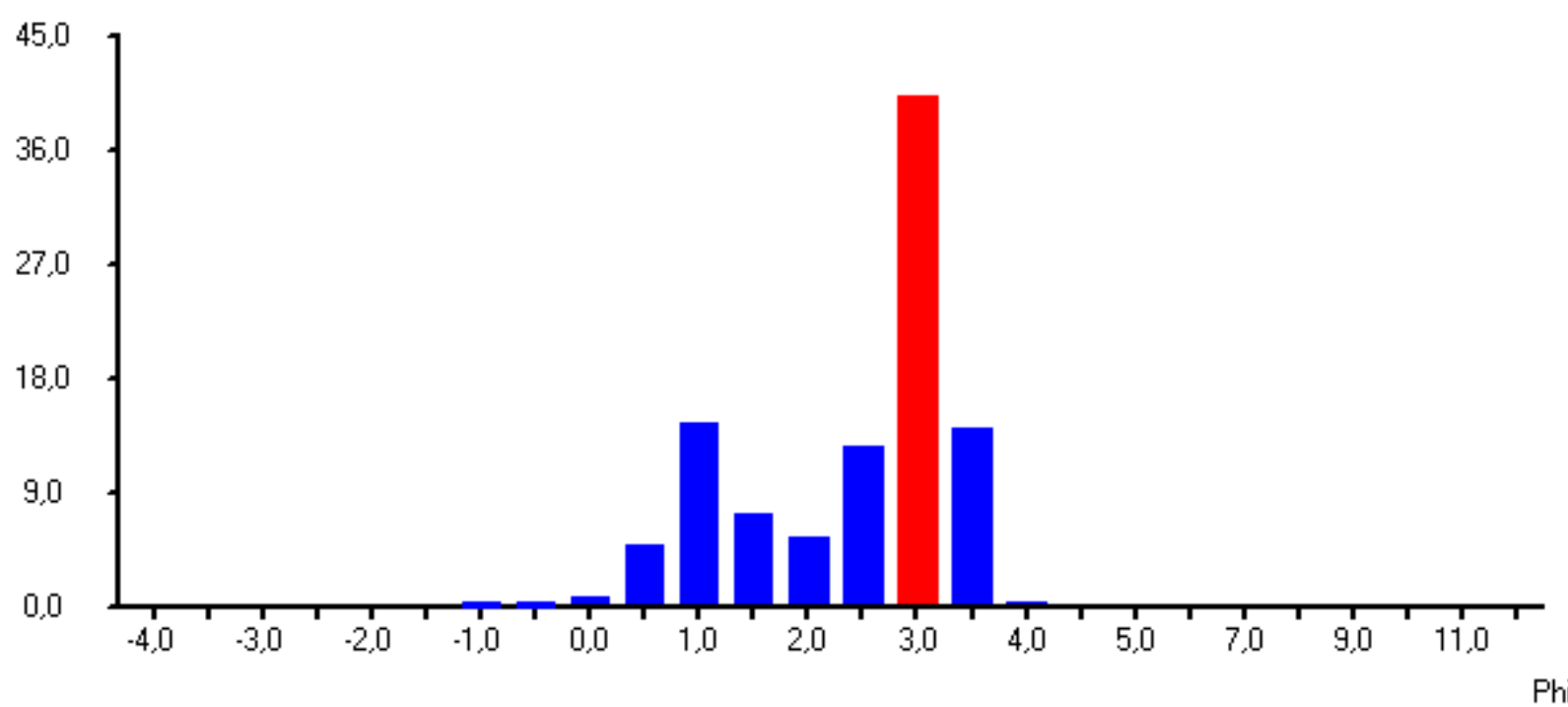

Figura 12: Histograma de frequência perfil 5 (estirâncio, período chuvoso)

Fonte: Organizado pelo autor. Amostra coletada em março de 2014 e tratada no Laboratório de Geologia e Geomorfologia Costeira e Oceânica (LGCO) da Universidade Estadual do Ceará (UECE).

Na praia de Maramar, os resultados sugerem tendência de progradação da linha de costa evidenciada por uma redução de energia dos agentes, verificada através da consequente deposição de partículas de calibre reduzido. Há também a presença de areias finas na zona de arrebentação de perfis localizados na praia de Maramar, o que é pouco comum na praia de Macapá, embora ambas sejam adjacentes.

O perfil 3 foi o que apresentou comportamento sazonal mais evidente. Sua posição central e com maior exposição em relação à ação dos ventos e das ondas, o fato de não sofrer diretamente os efeitos da morfodinâmica fluvial e da corrente de maré, que atua no canal fluvial, ajudam a explicar esses resultados encontrados.

Já as frações de areia fina, encontradas no perfil 5, se devem à sua localização em uma pequena reentrância e à presença de arenitos de praia. Assim, esses fatores limitam a circulação sedimentar, atenuando os efeitos da sazonalidade atmosférica. Dessa forma, a correlação atmosfera e dinâmica sedimentar mostra-se positiva nos perfis 3,4 e 5, e negativa nos perfis 1 e 2 . 


\section{CONSIDERAÇÕES FINAIS}

Verificou-se, ao longo dos cinco perfis, que a textura dos sedimentos é composta predominantemente por areias, que variam de areias finas a areias muito grossas. Há a ocorrência de frações de areia muito fina em frequência pouco significativa. Não foram encontradas frações de silte e argila.

Os perfis localizados na praia de Macapá não apresentaram comportamento sazonal em relação a granulometria dos sedimentos. Os fatores locais assumem, nesse caso, maior importância que a atmosfera. Assim, a morfodinâmica fluvial e as correntes de marés terão influência maior que as variáveis climáticas.

Alguns perfis apresentam mudanças sazonais no calibre médio dos sedimentos, uns de forma mais perceptível, como no 3, onde a areia fina é alterada para areia grossa. Isso se deve especialmente a sua localização no arco praial, estando mais exposto à ação das ondas e dos ventos. Portanto, mais suscetível às variações sazonais da atmosfera. O comportamento cíclico dos sedimentos na praia de Maramar (perfis 3, 4 e 5) revelam a correlação positiva entre a dinâmica atmosférica (e oceanográfica) e a morfodinâmica de praia.

\section{REFERÊNCIAS}

AB'SABER, A. N. Fundamentos da geomorfologia costeira do Brasil atlântico inter e subtropical. Revista Brasileira de Geomorfologia, [s.1.], v. 1, n. 1, p. 27-43, 2000.

ALVES, J. M. B.; REPELLI, C. A. A variabilidade pluviométrica no setor Norte do Nordeste e os eventos El Niño-Oscilação Sul (ENOS). Revista Brasileira de Meteorologia, [s.1.], v. 7, n. 2, p. 583-92, 1992.

ALVES, J. M. B. et al. Movimento vertical e índices atmosféricos associados às células de hadley e walker em anos de contrastes climáticos: relação com chuvas do setor Norte do Nordeste do Brasil (SNNEB). Revista Brasileira de Meteorologia, [s.1.], v. 20, n. 1, p. 15-36, 2005.

AYODE, J. O. Introdução à climatologia para os trópicos. 12. ed. Rio de Janeiro: Bertrand Brasil, 2007.

BITTENCOURT, C. da S. P. et al. Variações texturais induzidas pelo vento nos sedimentos da face da praia (Praia de Atalaia, Piauí). Revista Brasileira de Geociências, [s.1.], v. 20, p. 201 - 207, 1990.

FEITOSA, A. C. Dinâmica dos processos geomorfológicos na área costeira a nordeste da ilha do Maranhão. 1996. 249 f. Tese (Doutorado em Geografia) - Instituto de Geociências e Ciências Exatas, Universidade Estadual Paulista, Rio Claro, 1996.

FOLK, R. L. Petrology of sedimentary rocks. Austin: The University of Texas, 1968. 
HASTENRATH, S.; HELLER, L. Dynamics of climatic hazards in northeast Brazil. Quarterly Journal Royal Meteorology Society, [s.1.], v. 103, n. 435, p. 77-92, 1977.

INSTITUTO NACIONAL DE METEOROLOGIA (INMET). Normais climatológicas do Brasil 1961-1990. Brasília: INMET, 2009.

INSTITUTO NACIONAL DE METEOROLOGIA (INMET). Banco de Dados Meteorológicos para Ensino e Pesquisa (BDMEP) do Instituto Nacional de Meteorologia. [2011]. Disponível em: <http://www.inmet.gov.br/portal/index.php?r=bdmep/bdmep.> Acesso em: 22 jan. 2015.

INSTITUTO NACIONAL DE PESQUISAS ESPACIAIS (INPE). Centro de Previsão de Tempo e Estudos Climáricos (CPTEC). 2015a. Disponível em: <http://ondas.cptec.inpe.br/>. Acesso em: 01 maio 2015.

INSTITUTO NACIONAL DE PESQUISAS ESPACIAIS (INPE). Divisão de Satélite e Sistemas Ambientais (DSSA). Satélite GOES. 2015b. Disponível em:

<http://satelite.cptec.inpe.br/home/novoSite/index.jsp.> Acesso em: 01 maio 2015.

INSTITUTO NACIONAL DE PESQUISAS ESPACIAIS (INPE). Divisão de Satélite e Sistemas Ambientais (DSSA). Satélite LADSAT. 2015c. Disponível em: <http://www.dgi.inpe.br/CDSR/>. Acesso em: 01 maio 2015.

LIMA, F. C. da S. Condicionantes geoambientais e alternativas de sustentabilidade Macapá/Luís Correia-PI. 2005. 154 f. Dissertação (Mestrado em Desenvolvimento e Meio Ambiente) - Programa Regional de Pós-Graduação em Desenvolvimento e Meio Ambiente (PRODEMA), Universidade Federal do Piauí (UFPI), 2005.

MELO, A. B. C.; CAVALCANTI, I. F de A.; SOUZA, P. P. Zona de convergência intertropical do Atlântico. In: CAVALCANTI, I. F. A. et al (Org.). Tempo e clima no Brasil. São Paulo: Oficina de Texto, 2009. P. 25 - 42.

MONTEIRO, C. A. F. Análise rítmica em Climatologia - problemas da atualidade climática em São Paulo e achegas para um programa de trabalho. Climatologia 1, USP/IG, São Paulo, 1971.

MORAIS, J. O. et al. Hazards and managemant as a consequence of the gabions emplancement at Caponga Beach Ceará/ Brazil. Journal of Coastal Research, [s.1.], Special Issue 39, 2004.

MOURA, A. D.; SHUKLA, J. On the dynamics of droughts in northeast Brazil: observations, theory and numerical experiments with a general circulation model. Journal of the Atmospheric Science, [s.1.], v. 38, n. 12, p. 2653-2675, 1981.

MUEHE, D. (Org.). Erosão e progradação do litoral brasileiro. Brasília: Ministério do Meio Ambiente, 2006.

MUEHE, D. Geomorfogia costeira. In: GUERRA, A. J. T; CUNHA, S. B. (Org). Geomorfologia: exercícios, técnicas e aplicações. 5. ed. Rio de Janeiro: Bertrand Brasil, 2011. p.191-238.

NÍMER, E. Circulação atmosférica do Brasil: contribuição ao estudo de climatologia dinâmica do Brasil. Revista Brasileira de Geografia, Rio de Janeiro, 1976. 
NÍMER, E. Clima. In: INSTITUTO BRASILEIRO DE GEOGRAFIA E ESTATÍSTICA (IBGE). Geografia do Brasil: região Nordeste. Rio de Janeiro: IBGE, 1977.

NOBRE, P.; SHUKLA, J. Variations of sea surface temperatures, wind stress and rainfall over the Tropical Atlantic and South America. Journal of Climate, [s.1.], v. 9, n. 10, p. 2464- 2479, 1996.

PAULA, J. E. A. de. Dinâmica morfológica da planície costeira do estado do Piauí: evolução, comportamento dos processos costeiros e a variação da linha de costa. 2013. $247 \mathrm{f}$. Tese (Doutorado em Ciências Marinhas Tropicais) - Programa de Pós-Graduação em Ciências Marinhas Tropicais. Instituto de Ciências do Mar (Labomar), Universidade Federal do Ceará (UFC), 2013.

PHILANDER, S. G. El Niño, La Niña, and Southern Oscillation. Londes: Academic Press, 1990.

ROCHA, G. C. Impactos sócio-ambientais do processo de erosão costeira: subsídios ao planejamento e gestão na praia da Caponga - Cascavel - CE. 2008. 91 p. Dissertação (Mestrado em Geografia) - Centro de Ciências e Tecnologia, Universidade Estadual do Ceará, 2008.

ROCHA, G. C. Propostas para a elaboração de planos de gestão para a praia de Macapá Luis Correia - Piauí . 2015. 213 f. Tese (Doutorado em Geografia) - Instituto de Geociências e Ciências Exatas, Universidade Estadual Paulista, Rio Claro, 2015.

SORRE, M. Les fondements de la Gèographie Humaine. Paris: Armand Colin,1951.

SUGUIO, K. Geologia sedimentar. São Paulo: Edgard Blücher, 2003.

TAVARES, A. C. Critérios de escolha de anos padrões para análise rítmica. Revista Geografia, Rio Claro, v1, n1, p. $79-87,1976$.

TAVARES, A. C. Mudanças climáticas. In: VITTE, A. C.; GUERRA A. J. T. (Org.). Reflexões sobre a Geografia Física no Brasil. Rio de Janeiro: Bertrand Brasil, 2004. p. 49-88.

WALKER, G. T; BLISS, E. W. World Weather V. Memorial Royal of Meteorological Society, [s.1.], v. 4, n. 36, p. 53-84, 1932. 